\title{
Utilidad de la clínica en el diagnóstico de vaginitis
}

\section{Objetivo}

Evaluar el rol del examen clínico y determinar los coeficientes de probabilidad* positivos y negativos de los distintos signos y síntomas para el diagnóstico de vaginitis candidiásica, vaginosis bacteriana y tricomoniasis.

\section{Fuentes de datos}

MEDLINE (1966-2003); American College of Obstetricians and Gynecologists Technical Bulletin.

\section{Selección de estudios y extracción de los datos}

Se incluyeron estudios sobre mujeres premenopáusicas sintomáticas evaluadas en atención primaria. Los tests fueron evaluados sólo si proveían información diagnóstica en el transcurso de una entrevista de consultorio y eran comparados con un test de referencia* aceptable (cultivo positivo para cándida o tricomonas o identificación de levaduras por microscopia y criterios de Ansel para vaginosis (cumplir tres de los siguientes criterios: exudado vaginal homogéneo fino, células indicativas [clue cells], prueba de olor positiva y $\mathrm{pH}$ vaginal $>4,5$ ). Se valoró la calidad metodológica de los estudios usando una escala de tres niveles (nivel $1=$ calidad máxima). Los tres autores extrajeron los datos y evaluaron la sensibilidad y especificidad independientemente. La ausencia de definiciones estándar de los diferentes signos y síntomas hizo imposible combinar los resultados de los diferentes estudios.

\section{Resultados principales}

Dieciocho artículos cumplieron los criterios de inclusión y exclusión. $\mathrm{Ni}$ los síntomas ni los signos del examen físico permiten distinguir con exactitud entre las diferentes causas de vaginitis. Los tests diagnósticos pasibles de ser realizados en el consultorio (microscopia, test de las aminas y medición del pH) son la forma más útil de diagnosticar estas tres entidades. En la tabla se observan las características de las principales variables.
Tabla. Utilidad diagnóstica de las distintas variables para vaginitis

\begin{tabular}{|c|c|c|c|}
\hline Variable & Diagnóstico & $\begin{array}{c}\text { Coeficiente de } \\
\text { probabilidad } \\
\text { positivo* o rangos } \\
\text { (IG95\%) }\end{array}$ & $\begin{array}{l}\text { Goeficiente de } \\
\text { probabilidad } \\
\text { negativo* o } \\
\text { rangos (IB95\%) }\end{array}$ \\
\hline Ausencia de prurito & Candidiasis & (1) & $\begin{array}{c}0,18(0,05-0,7) \\
\text { a } 0,79(0,72-0,87)\end{array}$ \\
\hline Ausencia de olor & Vaginosis & - & $0,07(0,01-0,51)$ \\
\hline Flujo como "lecne cortada" & Candidiasis & $\begin{array}{l}6,1(2,5-14) \\
\text { a } 130(19-960)\end{array}$ & $\begin{array}{l}0,28(0,19-0,44) \\
\text { a } 0,86(0,8-0,93)\end{array}$ \\
\hline $\begin{array}{l}\text { Autodiagnóstico ('tengo otra } \\
\text { candidiasis") }\end{array}$ & Candidiasis & $3,3(1,2-9,1)$ & - \\
\hline Signos de inflamación & Candidiasis & $\begin{array}{l}2,1(1,5-2,8) \\
\text { a } 8,4(2,3-31)\end{array}$ & - \\
\hline Ausencia de olor & Candidiasis & $2,9(2,4-5)$ & - \\
\hline $\begin{array}{l}\text { Flujo como leche cortada + prurito } \\
\text { (signos combinados) }\end{array}$ & Candidiasis & $17(8,8-32)$ & - \\
\hline $\begin{array}{l}\text { Bacilos con motilidad "en } \\
\text { sacacorchos" }\end{array}$ & Vaginosis & $44(6,2-310)$ & - \\
\hline Levaduras en el extendido & Candidiasis & $\begin{array}{l}2,6(1,5-4,6) \\
\text { a } 31(4,4-220)\end{array}$ & - \\
\hline Lactobacilos escasos 0 ausentes & Vaginosis & $3,1(2,4-3,9)$ & - \\
\hline PH normal & Candidiasis & $\begin{array}{r}0,77(0,66-0,9) \\
\text { a } 7,2(3,4-15) \\
\end{array}$ & - \\
\hline Test de Aminas + & Candidiasis & $0,31(0,12-0,79)$ & - \\
\hline Tricomonas en el extendido & Tricomoniasis & $\begin{array}{c}4,5(0,1-217) \\
\text { a } 310(43-2200)\end{array}$ & - \\
\hline
\end{tabular}

\section{Conclusiones}

Ningún síntoma o signo tiene suficiente poder predictivo individualmente como para diagnosticar a ninguno de los tres patógenos. La microscopía es la mejor forma de hacer el diagnóstico siempre y cuando estén presentes los hallazgos típicos. Los síntomas y signos solamente pueden sugerir el diagnóstico o alejarlo.

Fuente de financiamiento: Sin conflictos de interés.

\section{Comentario}

Los síntomas vaginales son uno de los motivos de consulta ginecológicos más frecuentes. Tradicionalmente, los clínicos han diagnosticado candidiasis, vaginosis o tricomoniasis basándose en una combinación de datos del examen físico, el pH, el uso del microscopio y el test de las aminas'. En la práctica, no se ve una buena correlación entre el diagnóstico clínico y los cultivos, lo cual motivó la realización de este trabajo. Como se menciona en las conclusiones, resultaría problemático intentar hacer el diagnóstico basándose exclusivamente en síntomas y signos individuales, y la microscopía es la mejor forma de hacer el diagnóstico siempre y cuando estén presentes los hallazgos típicos. Sin embargo, la mayoría de los médicos no realiza el extendido vaginal y valdría la pena preguntarse porqué. En caso de contar con un microscopio, existe un recurso gratis y muy útil para aprender a realizar este procedimiento, que requiere de cierto entrenamiento básico: http://depts.washington.edu/nnptc/online_training/wet_preps.html. En los casos en los que no se cuenta con el mismo, se podría decir que si el cuadro clínico sugiere claramente una de las entidades, podría intentarse un tratamiento de monoterapia empírico y/o con- tinuar buscando hacer el diagnóstico de tricomonas o candida, así como considerar otras causas menos frecuentes de vaginitis (gonorrea, clamidia, herpes, HPV). Por otro lado, podría ser que no sea un patógeno el causante del cuadro, ya que el flujo normal puede ser maloliente y acompañarse de síntomas irritativos en algunos casos, por lo que también se podría adoptar una conducta expectante en acuerdo con la paciente.

\section{Conclusiones del comentador:}

Los resultados de este trabajo tienden a resaltar la importancia de realizar el extendido vaginal en el consultorio para el diagnóstico de las vaginitis en caso de contar con los medios, ya que permite alcanzar una mayor certeza diagnóstica. En caso de no contar con un microscopio, resulta valioso conocer el valor predictivo positivo y negativo real de los diferentes signos y síntomas y de la combinación de los mismos, a fin de reconocer sus limitaciones para el diagnóstico de las diferentes entidades.

1. Doust $\mathrm{J}$ (comentador). Review: vaginal signs and symptoms perform poorly in diagnosing vaginal candidiasis, bacterial vaginosis, and vaginal trichomoniasis. Evid Based Med 20049 : 153 